\title{
BMJ Open Compliance with the proper use of an individual radiation dosimeter among children and the effects of improper use on the measured dose: a retrospective study 18-20 months following Japan's 2011 Fukushima nuclear incident
}

\author{
Shuhei Nomura, ${ }^{1}$ Masaharu Tsubokura, ${ }^{2,3}$ Ryugo Hayano, ${ }^{4}$ Daisuke Yoneoka, ${ }^{5}$ \\ Akihiko Ozaki, ${ }^{2}$ Yuki Shimada, ${ }^{2}$ Tomoyuki Furutani, ${ }^{6}$ Yukio Kanazawa, ${ }^{2}$ \\ Tomoyoshi Oikawa ${ }^{2}$
}

To cite: Nomura S,

Tsubokura M, Hayano R, et al. Compliance with the proper use of an individual radiation dosimeter among children and the effects of improper use on the measured dose: a retrospective study $18-$ 20 months following Japan's 2011 Fukushima nuclear incident. BMJ Open 2015;5: e009555. doi:10.1136/ bmjopen-2015-009555

- Prepublication history for this paper is available online. To view these files please visit the journal online (http://dx.doi.org/10.1136/ bmjopen-2015-009555).

Received 28 July 2015 Revised 20 October 2015 Accepted 28 October 2015

CrossMark

For numbered affiliations see end of article.

Correspondence to Dr Tomoyoshi Oikawa; minamisoma-kyukyu@bz04. plala.or.jp

\section{ABSTRACT}

Objectives: To identify profiles of children who did not properly use individual radiation dosimeters following Japan's 2011 Fukushima nuclear incident, and to assess how much error is generated by improper dosimeter use.

Participants: The participants in this study comprised 1637 school children who participated in the external radiation exposure screening programme administrated by Minamisoma City (located $20-30 \mathrm{~km}$ from the Fukushima nuclear plant) between 18 and 20 months after the Fukushima incident.

Methods: We assessed the factors associated with improper use (non-use) of the dosimeters at specific time periods during the day (school commuting hours, at school, at home, outdoors and at bedtime) using logistic regression analyses. Ratios of the measured dose to regression estimates of the 'expected' dose (referred to as an error due to non-use) were also examined.

Results: Only 119 children (7.3\%) used the dosimeters properly in all time periods. This low rate was attributed primarily to non-use when children were in the home and outdoors, rather than at school.

School level, air dose rate at home, gender, membership in outdoor sports clubs and time spent outdoors on weekends, were significantly associated with improper use, after adjustment for covariates. Data from children who did not wear the dosimeters to school and outdoors had statistically significant (but clinically insignificant) errors (ratio: $1.13, p<0.01$; and $0.97, p<0.05$, respectively), whereas improper use of the dosimeters at school, at home and at bedtime did not generate significant errors.

Conclusions: Well-targeted rigorous instructions on the use of the dosimeter are required, with particular focus on time periods other than school hours. However, given the small dose error due to the improper use of the dosimeters, even if the dosimeters

\section{Strengths and limitations of this study}

- We undertook the first study after Japan's 2011 Fukushima nuclear incident, to identify profiles of children who did not properly use individual radiation dosimeters and to assess how much error is generated by improper dosimeter use.

- The external radiation screening programme, administrated by Minamisoma City, included a self-report survey with regard to the lifestyle of the participants at home and at school, as well as the conditions under which the dosimeters were worn, which enabled us to assess how well the programme participants used the dosimeters.

- Because the absolute values of the errors generated by improper dosimeter use may depend on radiation levels in the area, our findings with regard to the clinical significance of the errors may not be generalisable to other areas with higher exposure levels in the Fukushima Prefecture.

are improperly used, solid evaluation of the radiation exposure may be possible with some accuracy.

\section{INTRODUCTION}

After a major nuclear incident, radiation exposure is a public health issue. ${ }^{1}{ }^{2}$ Following Japan's Fukushima Daiichi Nuclear Power Plant incident, triggered by the Great East Japan Earthquake and subsequent tsunami on 11 March 2011, health concerns have arisen in the radiation-contaminated areas. Years after the incident, owing to 
successful governmental control of contaminated food, the dose from internal exposure has been marginal; ${ }^{3-6}$ accordingly, as Tsubokura et $a l^{7}$ acknowledged, a large proportion of the dose can be attributed to external radiation exposure. Assessment of external exposure is, hence, a major component of the current risk management of human health.

Dose can be assessed using either of the following two approaches: (1) mathematical model estimation with reasonable scientific assumptions or (2) direct individual dose measurements. ${ }^{28}$ The estimation of the dose from external exposure is based on the level of air or soil contamination with due consideration of exposure attenuation, which is a function of personal and environmental factors (often referred to as radiation reduction factors). On the contrary, direct dose measurements are performed using an individual radiation dosimeter.

Quickness and flexibility are the main features of the modelling approach; modelling can provide estimated dose levels for individual as well as for representative members of the public, depending on the possible exposure scenarios. However, accuracy can be a significant challenge in its successful application in dose assessment. $^{9-11}$ Following the Fukushima incident, according to Nomura $e t a l^{12}$ and Naito et al, ${ }^{9}$ the dose estimated using a reconstruction model developed by the Japanese government was about three times higher than that measured by an individual dosimeter. This disagreement arises primarily from uncertainties due to limited or incomplete information on the radiation reduction factors. ${ }^{12}$

However, to respond to the growing concern from individuals in affected areas, to identify entry points for local action, and to develop strategy directions for local policy and practice, direct measurement can be a desirable dose assessment approach because it is easy to perform, with fewer scientific uncertainties, and can consider any individual specificity. ${ }^{13}{ }^{14}$ However, as Nomura et $a l^{12}$ reported, children at the greatest risk for future health issues do not necessarily use the individual dosimeters properly, which may present an obstacle to the direct measurement approach because it likely influences the measurement values. Hence, to better understand issues associated with the use of individual dosimeters, and to determine appropriate evaluation and protection methods with respect to radiation exposure in the present Fukushima incident as well as for future radiological incidents, the objective of this study was twofold: (1) to identify profiles of children who do not use the dosimeters correctly after the Fukushima incident and (2) to assess how much error is generated by improper use of the dosimeters.

\section{METHODS}

\section{Data collection}

\section{Settings}

The study site is Minamisoma City, located $14-38 \mathrm{~km}$ from the Fukushima Daiichi Nuclear Power Plant. In response to public requests, since 1 October 2011, 6 months after the Fukushima incident, the city office of Minamisoma has offered a free screening programme for external radiation exposure for infants, school children and pregnant women who reside in the city. The programme notification was released on the official website of Minamisoma Municipal General Hospital (MMGH). The geographical location of Minamisoma City relative to the nuclear power plant is shown in figure 1 .

The screening programme has been implemented once every 3 months. First, the city office mails a radiation dosimeter (Glass Badge: GD-450, Chiyoda Technol Corp) to the programme participants, together with an
Figure 1 Geographical location of Minamisoma City. Base map indicates the air dose rate $(\mu \mathrm{Sv} / \mathrm{h})$ as of 28 June 2012. Blue circles show the geographical distribution of the study participants, where the sizes of the circles are proportional to the number of participants living in each district.

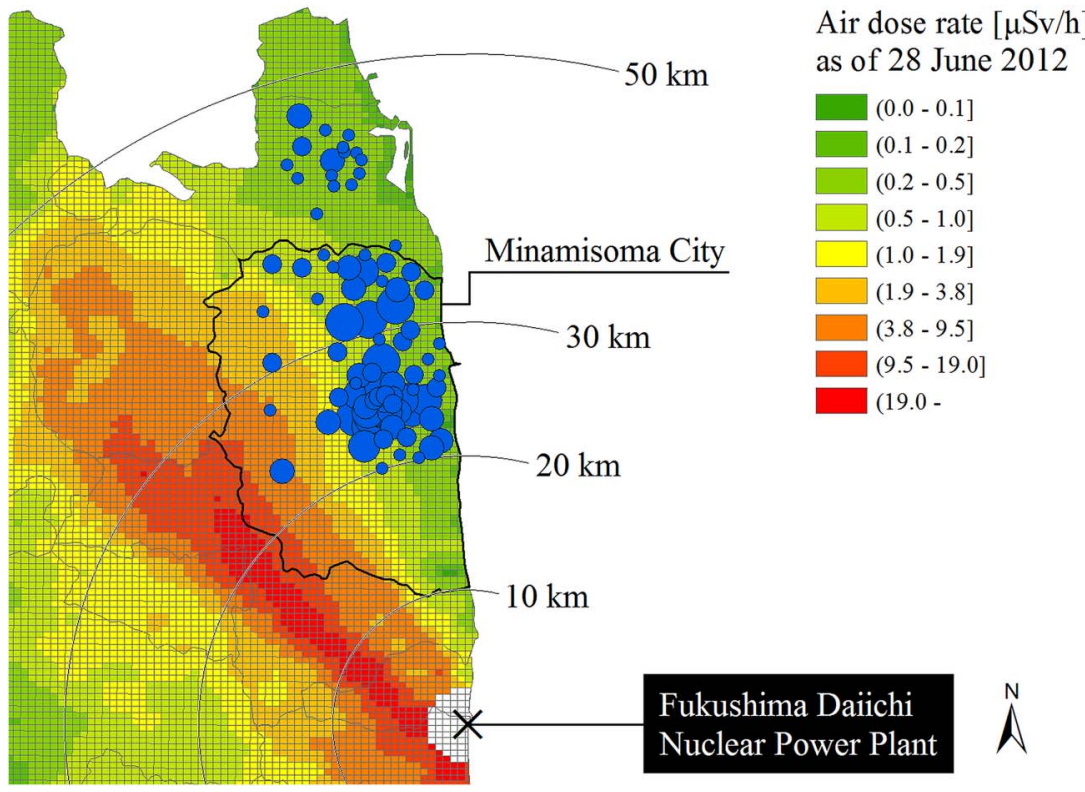

Air dose rate $[\mu \mathrm{Sv} / \mathrm{h}]$ as of 28 June 2012 
equipment instruction manual for the use of the dosimeter. After the 3-month measurement is completed, the dosimeter is returned to the city office and the measured value of the dose is recorded at MMGH. Note that a few dosimeters were lost during the programme, and we did not include those individuals who lost their dosimeters in this study. The instruction manual explains that the dosimeter needs to be hung from the user's neck throughout the day, except when the user is at home, in which case the dosimeter can be placed near the user.

For school children, this programme also includes a brief self-report survey with regard to their lifestyle at home and at school during the screening. This survey also contains questions on the conditions under which the Glass Badge is worn, which makes it possible to assess how well the programme participants used the dosimeters. The answer sheet is returned to the city office along with the dosimeters.

\section{Study participants and data}

We considered school children who participated in the fourth screening programme, which was conducted between 1 September and 30 November 2012, because of the large number of screening participants. As noted above, the analytical data set contained dose records and self-report survey results. The 3-month radiation dose $(\mathrm{mSv})$ was measured in terms of a dose equivalent at a tissue depth of $1 \mathrm{~cm}(\mathrm{Hp}(10)) .{ }^{15}$ The dose attributed to the natural background from cosmological sources and the earth was subtracted from the original Glass Badge dose measurements by default; therefore, the dose data we obtained was the 'additional' dose after the Fukushima incident. The subtracted value was $0.14 \mathrm{mSv}(0.56 \mathrm{mSv} /$ year $)$, which was measured before the incident by Chiyoda Technol Corp at Oarai, Ibaraki Prefecture, located more than $100 \mathrm{~km}$ south of the Fukushima nuclear plant. ${ }^{16}$ Owing to geographical variation in the background dose and the measurement errors of the Glass Badge, the additional dose of some participants was below zero after automatic subtraction of this background dose, causing a left-censoring effect at $0 \mathrm{mSv}$. However, for easier clinical and policy interpretation, we re-added this dose value to the collected data. This means that the Glass Badge measurements of the additional dose were replaced with measurements of 'total' doses; accordingly, the data were left-censored at $0.14 \mathrm{mSv}$. Note that the lower limit of the measurable dose of the Glass Badge was $0.1 \mathrm{mSv}$ and the range of accuracy of the Glass Badge measurement of the cumulative dose in 35 days was $\pm 4 \%$. ${ }^{17}$ The $\mathrm{Hp}(10)$ value measured under geometrical conditions in Fukushima is known to be comparable with the effective dose obtained using isotropic or rotational irradiation geometries. ${ }^{10} 18$ The effective dose is the weighted sum of the equivalent doses to various tissues and organs.

The self-report survey data contained information on the participants' behaviour for each time period in a day: at home (eg, room where most daytime hours were spent, storey on which this room is located, sleeping place, storey on which sleeping place is located); commuting time (eg, school commuting time, school commuting means); at school (eg, seat position in the classroom, number of times outdoor exercise was done per week, place where most lunch break hours were spent); and after school and on weekends (eg, place where most after-school hours were spent, hours spent outdoors after school, place where most daytime hours were spent on holiday, hours spent outdoors on weekends). The survey data also included the conditions under which the Glass Badge was worn during the following time periods: travel to school (whether the dosimeters were worn (brought) to school); at school (whether the dosimeters were worn at school); at home (whether the dosimeters were worn at home); outdoors (whether the dosimeters were worn (brought) outdoors) and at bedtime (whether the dosimeters were worn when sleeping).

Furthermore, the air dose rates at the participants' dwelling location and school were also considered (see the following sections).

\section{Air dose rate at home}

We collected data from the official website of the Ministry of Education, Culture, Sports, Science, and Technology (MEXT). After the Fukushima incident, MEXT performed airborne radiation monitoring at irregular intervals within a radius of $80 \mathrm{~km}$ around the nuclear power plant. The flight altitude for this monitoring is approximately $150-300 \mathrm{~m}$ above the ground, and the width of the flight path of the aircraft is about $1.85 \mathrm{~km}$. The recorded value is the average of the measured values within a circle of around $600 \mathrm{~m}$ in diameter under the aircraft. The results of this MEXT monitoring are open access, and the data available online contain the air dose rate $(\mu \mathrm{Sv} / \mathrm{h})$ at a height of $1 \mathrm{~m}$ above the ground, measured in terms of the ambient dose equivalent $\left(\mathrm{H}^{*} 10\right),{ }^{15}$ which includes the natural radiation background from the earth, ${ }^{19}$ and the corresponding latitude and longitude coordinates of the monitoring points.

The air dose rate at each participant's dwelling location was then estimated as follows. First, because the fourth Glass Badge screening programme was conducted between 1 September and 31 November 2012, and the MEXT monitoring occurred twice in 2012 (28 June and 16 November), ${ }^{20} 21$ a time interpolation method was applied to estimate the air dose rate in the screening period. Then, the MEXT monitoring results were averaged using a $500 \mathrm{~m}^{2}$ mesh on the basis of the Japan Profile for Geographical Information Standards (elevation and slope angle fourth mesh data), ${ }^{22}$ which was developed and released by the Ministry of Land, Infrastructure and Transport, Japan, such that each participant's household belonged to a mesh area. This 
approach enabled estimation of the air dose rate at each participant's household during the screening period.

\section{Air dose rate at school}

The Fukushima Prefecture conducted air dose monitoring between 19 June and 11 July 2012, for each school in Minamisoma City. Data available for public access contain air dose rates at a height of $1 \mathrm{~m}$ above ground on the school grounds and at the main gate and entrance/exit of the school, measured in terms of the ambient dose equivalent $\left(\mathrm{H}^{*} 10\right),{ }^{15}$ which included the natural radiation background from the earth.

\section{Data analysis}

The following two analyses were conducted.

Analysis 1: To identify the factors associated with improper use of the Glass Badge for the time periods in a day, a logistic regression model was constructed for each time period. The outcome measure was binary (1: not used, 0: equipped); thus, the regression results present the exponentiated form of the computed regression coefficients of each independent variable, indicating the change in the odds (ie, the OR) of non-use for a unit increase in the variable.

Analysis 2: To assess how much error is generated by improper use of the Glass Badge, we considered the following method. First, using the data from those who used the dosimeters properly (ie, the participants who used the dosimeters during all time periods in a day), we estimated a regression model that specified the relationships between the measured dose and the covariates. To build the model, a Tobit model was applied to the data, which enabled estimation of the linear relationships among variables, adjusting for the left-censoring effect of the Glass Badge. Given the potential outliers among the school children (ie, those who showed higher dose levels), the natural logarithm of the dose was used for the dependent variable. Second, we predicted the 'expected' dose values of those who used the dosimeters improperly, by fitting their parameters in this prediction model. Finally, the predicted dose and measured dose of each individual were compared in terms of the ratio of the measured to predicted values.

For regression modelling in these analyses, model selection was performed using a backward-stepwise method with p-to-remove set to $>0.05 .{ }^{23}$ Backward-stepwise regression starts with all candidate variables in the model and removes the least significant variables until all remaining variables are statistically significant. The partial F-test was used to verify the entry and removal of variables from the model. Variables that were known or suspected risk factors (eg, gender) were incorporated into the final model regardless of their statistical significance.

\section{Robustness of the regression prediction}

To assess the prediction accuracy of the Tobit model that we constructed for estimating the 'expected' dose in children who improperly used the Glass Badges, we built another prediction model using the classification and regression tree (CART) method. The CART method is a non-parametric method that does not require any assumptions regarding the distributions of the input data. ${ }^{24}$ Then, we compared the pseudo- $\mathrm{R}^{2}$ values from the CART model pruned by 10 -fold cross-validation with the deviance criterion rule to those from a Tobit model in order to examine which model provides a better dose prediction.

All statistical analyses were conducted using STATA/ MP V.13 and/or R V.3.2.0.

\section{RESULTS}

\section{Participants' characteristics}

Of the 1956 school children who participated in the fourth screening programme, we excluded those for whom basic data, including household addresses, were missing, and we analysed the remaining 1637 children. The demographic characteristics of the participants are summarised in table 1 . The majority of the participants were primary school children $(65.2 \%)$ and lived in a rural area $(69.0 \%)$. No substantial difference in gender was observed $(52.4 \%$ female). The mean air dose rates at a height of $1 \mathrm{~m}$ above the ground at home, on the school grounds, at the main gate and at the entrance/ exit of the school were $0.49,0.11,0.22$ and $0.17 \mu \mathrm{Sv} / \mathrm{h}$, respectively.

\section{Profiles of children who improperly used the Glass Badge}

Only 119 children (7.3\%) wore the Glass Badge during all time periods in a day (ie, used the dosimeters properly). As shown in table 1, a large gap between use at home and use at school was observed. Many did not use the dosimeters when they were at home $(70.3 \%)$ and sleeping $(69.2 \%)$. On the contrary, most of the children wore the dosimeters to school $(94.6 \%)$, and they were also likely to use the dosimeters at school $(70.5 \%)$.

Table 2 shows the results of logistic regression analyses to assess the relationships among non-use of the dosimeters and the covariates. After adjusting for the covariates, the school level was significantly associated with non-use at home, outdoors and at bedtime. Younger children (ie, primary/secondary school children) were significantly less likely to wear the dosimeters than were high school children. Other significant factors associated with non-use of the dosimeters were the air dose rate at home, gender, membership in outdoor sports clubs and hours spent outdoors on weekends. Children living in areas with a higher air dose rate at home had lower odds of non-use at school (OR 0.91 for $0.1 \mu \mathrm{Sv} / \mathrm{h}$ increase; $95 \%$ CI 0.85 to $0.98 ; \mathrm{p}<0.05$ ), indicating that children who had higher air contamination levels at home were more likely to wear the dosimeter at school. At school, males had higher odds of non-use than females (OR 1.34; 95\% CI 1.07 to $1.71 ; \mathrm{p}<0.05$ ). Those who belonged to outdoor sports clubs were less likely to 
Table 1 Demographic characteristics of participants

\begin{tabular}{|c|c|c|c|c|c|c|}
\hline \multirow[b]{2}{*}{ Variablet } & \multirow[b]{2}{*}{ Total number } & \multicolumn{5}{|c|}{ Amount (\%) of non-use } \\
\hline & & To school & At school¥ & At home & Outdoors & At bedtime \\
\hline \multicolumn{7}{|l|}{ School level } \\
\hline Primary & 1068 (65.2) & $55(5.2)$ & $287(28.3)$ & $785(73.5)^{\star \star}$ & $537(50.3)^{\star \star}$ & $788(73.8)^{\star \star \star}$ \\
\hline Secondary & $371(22.7)$ & $23(6.2)$ & $115(33.1)$ & $239(64.4)^{\star *}$ & $211(56.9)^{\star \star}$ & $232(62.5)^{\star \star \star}$ \\
\hline High & $198(12.1)$ & $11(5.6)$ & $55(29.4)$ & $127(64.1)^{\star \star}$ & $83(41.9)^{\star \star}$ & $113(57.1)^{\star \star \star}$ \\
\hline \multicolumn{7}{|l|}{ Gender } \\
\hline Male & $779(47.6)$ & $44(5.7)$ & $233(31.7)$ & $546(70.1)$ & $401(51.5)$ & $527(67.7)$ \\
\hline Female & $858(52.4)$ & $45(5.2)$ & $224(27.6)$ & $605(70.5)$ & $430(50.1)$ & $606(70.6)$ \\
\hline \multicolumn{7}{|l|}{ Dwelling area§ } \\
\hline Rural & $1130(69.0)$ & $69(6.1)$ & $316(29.8)$ & $814(72.0)^{*}$ & $566(50.1)$ & 798 (70.6) \\
\hline Urban & 507 (31.0) & $20(3.9)$ & $141(29.0)$ & $337(66.5)^{*}$ & 265 (52.3) & $355(66.1)$ \\
\hline Total & 1637 & $89(5.4)$ & $457(29.5)$ & $1151(70.3)$ & $831(50.8)$ & $1133(69.2)$ \\
\hline
\end{tabular}

use the dosimeters when they were outdoors (OR 1.38; $95 \%$ CI 1.00 to $1.90 ; \mathrm{p}<0.05)$. Similarly, the odds of non-use among children who spent more than $2 \mathrm{~h}$ outdoors on weekends were 1.53 times higher than those of children who spent $<30$ min outdoors (95\% CI 1.14 to 2.06; $\mathrm{p}<0.01$ ), indicating that children who spent more time outdoors were less likely to wear the dosimeters outdoors. Whether or not the dosimeters were worn to school was not associated with any variables.

\section{Comparison of measured dose versus regression estimates of dose}

The data from the 119 children who properly used the Glass Badges were employed to construct the dose prediction model. The estimated model included the following variables: air dose rate at home and on school grounds, gender, dwelling area, school level, floor of room where most daytime hours were spent at home, floor of sleeping place, seat position in the classroom, and hours spent outdoors after school and on holiday. Using this model, the 'expected' dose values of the remaining children $(n=1518)$ were predicted. The measured and predicted doses are compared in table 3 . Although the overall comparison showed no statistically significant difference between the measured and predicted doses, time period-specific comparisons of 'to school' and 'outdoors' showed significant differences. The mean measured dose of those who wore the dosimeters to school was higher than their predicted dose by $0.04 \mathrm{mSv}(\mathrm{p}<0.01$ : paired t test), representing a $13 \%$ difference from the predicted value. In addition, the measured dose of children who did not wear the dosimeters outdoors was $0.01 \mathrm{mSv}$ lower than the predicted dose on average $(p<0.05)$, indicating a $3 \%$ difference.

\section{Robustness of the regression prediction}

The pseudo- $\mathrm{R}^{2}$ values from the Tobit model were compared with those from a CART model pruned by 10 -fold cross-validation with the deviance criterion rule to assess the prediction accuracy of the Tobit model. As a result, we obtained values of 0.86 for the Tobit model and 0.70 for the CART model, indicating that the Tobit model was slightly more predictive.

\section{DISCUSSION}

Following radiation-release incidents, rigorous evaluation of radiation exposure is fundamental for better understanding of the future health risks as well as for effective radiation protection planning. After the Fukushima incident, because of limited scientific evidence and knowledge with regard to dose reconstruction, we have faced inaccuracy in the government dose estimation model. ${ }^{9} 12$ Hence, to ensure as much accuracy as possible, direct dose measurements using individual radiation dosimeters have been adopted by many local authorities as a major component of their radiation protection policies. ${ }^{14}$ However, evaluations of proper dosimeter use by individuals is greatly lacking; the errors arising from improper use of the dosimeters are also unknown because of lack of information on users' daily behaviour and the conditions under which the dosimeters are worn. Here, the external radiation screening programme provided by Minamisoma City offered a unique and valuable opportunity to address these questions. This is the first study evaluating compliance with the proper use of an individual radiation dosimeter in children and the effects of improper use on the measured dose after a major radiation-release incident.

Our study showed that only $7.3 \%$ of the participants used the Glass Badges properly during the screening period, and some tendencies with regard to dosimeter use were identified to suggest potential reasons for this low rate. First, it must be emphasised that, although only a few per cent of the children used the dosimeters correctly, the use conditions by daily time period show that 
Table 2 OR and $95 \% \mathrm{Cl}$ of non-use of the Glass Badge

\begin{tabular}{|c|c|c|c|c|c|}
\hline Variable & To school & At school & At home & Outdoors & At bedtime \\
\hline Air dose rate at home $(0.1 \mu \mathrm{Sv} / \mathrm{h})$ & $0.89(0.78-1.02)$ & $0.91(0.85-0.98)^{\star}$ & $0.98(0.92-1.04)$ & $0.97(0.91-1.02)$ & $0.94(0.88-1.01)$ \\
\hline \multicolumn{6}{|l|}{ School level } \\
\hline Primary & $0.94(0.42-2.12)$ & $1.32(0.76-2.28)$ & $1.09(0.75-1.58)$ & $1.79(1.25-2.56)^{\star *}$ & $1.23(0.85-1.80)$ \\
\hline Secondary & $0.66(0.30-1.45)$ & $0.86(0.53-1.37)$ & $1.68(1.19-2.36)^{\star \star}$ & $1.39(1.02-1.91)^{\star}$ & $2.00(1.42-2.81)^{\star \star \star}$ \\
\hline High & 1.00 & 1.00 & 1.00 & 1.00 & 1.00 \\
\hline \multicolumn{6}{|l|}{ Gender } \\
\hline Male & 1.00 & $1.34(1.07-1.71)$ * & 1.00 & 1.00 & 1.00 \\
\hline Female & $0.89(0.57-1.38)$ & 1.00 & $1.11(0.89-1.38)$ & $1.01(0.82-1.24)$ & $1.20(0.94-1.53)$ \\
\hline \multicolumn{6}{|l|}{ Dwelling area } \\
\hline Rural & 1.00 & 1.00 & 1.00 & 1.00 & 1.00 \\
\hline Urban & $0.67(0.39-1.15)$ & $0.87(0.66-1.14)$ & $0.77(0.61-0.98)^{*}$ & $1.06(0.85-1.32)$ & $0.81(0.62-1.06)$ \\
\hline \multicolumn{6}{|l|}{ School commuting time (h) } \\
\hline$<0.5$ & 1.00 & - & - & - & - \\
\hline$>0.5$ & $0.87(0.43-1.78)$ & - & - & - & - \\
\hline \multicolumn{6}{|l|}{ School commuting means } \\
\hline Walk/bicycle & 1.00 & - & - & - & - \\
\hline Car & $1.43(0.81-2.50)$ & - & - & - & - \\
\hline Bus & $1.94(0.74-5.12)$ & - & - & - & - \\
\hline \multicolumn{6}{|l|}{ Sports clubs (outdoors) } \\
\hline No & - & 1.00 & - & 1.00 & - \\
\hline Yes & - & $0.73(0.51-1.04)$ & - & $1.38(1.00-1.90)^{\star}$ & - \\
\hline \multicolumn{6}{|l|}{ Sports clubs (indoors) } \\
\hline No & - & 1.00 & - & - & - \\
\hline Yes & - & $0.88(0.66-1.18)$ & - & - & - \\
\hline \multicolumn{6}{|l|}{ Seat position in the classroom } \\
\hline Window area & - & 1.00 & - & - & - \\
\hline Centre area & - & $1.08(0.81-1.42)$ & - & - & - \\
\hline Passage area & - & $0.97(0.69-1.36)$ & - & - & - \\
\hline Not decided & - & $1.06(0.68-1.65)$ & - & - & - \\
\hline \multicolumn{6}{|c|}{ Room where most daytime hours were spent at home } \\
\hline Living (family) room & - & - & 1.00 & - & - \\
\hline Own room & - & - & $1.22(0.84-1.77)$ & - & - \\
\hline \multicolumn{6}{|c|}{ Floor of room where most daytime hours were spent at home } \\
\hline 1st floor & - & - & 1.00 & - & - \\
\hline 2nd floor or higher & - & - & $0.85(0.61-1.17)$ & - & - \\
\hline \multicolumn{6}{|c|}{ Hours spent outdoors on weekends (h) } \\
\hline$<1$ & - & - & - & 1.00 & - \\
\hline $1-2$ & - & - & - & $1.01(0.79-1.29)$ & - \\
\hline$>2$ & - & - & - & $1.53(1.14-2.06)^{\star *}$ & - \\
\hline \multicolumn{6}{|l|}{ Sleeping place } \\
\hline Living (family) room & - & - & - & - & 1.00 \\
\hline Own room & - & - & - & - & $0.88(0.58-1.34)$ \\
\hline \multicolumn{6}{|l|}{ Floor of sleeping place } \\
\hline 1st floor & - & - & - & - & 1.00 \\
\hline 2nd floor or higher & - & - & - & - & $0.89(0.68-1.17)$ \\
\hline
\end{tabular}


Table 3 Comparison of the measured dose and regression estimates of dose (mSv) $(n=1518)$

\begin{tabular}{|c|c|c|c|}
\hline & $\begin{array}{l}\text { Measured } \\
\text { dose (SD) }\end{array}$ & $\begin{array}{l}\text { Estimated } \\
\text { dose (SD) }\end{array}$ & Ratios (SD) \\
\hline Overall & $0.33(0.11)$ & $0.33(0.09)$ & $0.99(0.35)$ \\
\hline \multicolumn{4}{|l|}{ Time period } \\
\hline To school & $0.37(0.14)$ & $0.32(0.07)$ & $1.13(0.43)^{\star \star}$ \\
\hline At school & $0.32(0.10)$ & $0.33(0.09)$ & $0.98(0.31)$ \\
\hline At home & $0.33(0.11)$ & $0.33(0.09)$ & $0.99(0.34)$ \\
\hline Outdoors & $0.32(0.10)$ & $0.33(0.09)$ & $0.97(0.33)^{\star}$ \\
\hline At bedtime & $0.33(0.11)$ & $0.33(0.09)$ & 0.99 (0.35) \\
\hline
\end{tabular}

most of the children used the dosimeters properly during school hours (table 1). Therefore, the low rate of proper use was attributed mainly to non-use when children were at home or outdoors, implying that parents were specifically concerned about the radiation exposure of their children at school (rather than at home or outdoors), where the children spent most of the day away from parental supervision. The practical implication is that more rigorous instructions on the use of the dosimeter are required, with particular focus on time periods other than on school hours.

Second, primary and secondary school children were significantly less likely to wear the dosimeters at home, outdoors or at bedtime than were high school children (table 2), suggesting that it is very difficult to encourage younger children to adhere to the appropriate use of the dosimeters, possibly because the children found it difficult to handle the small dosimeters. Thus, another important implication is that younger children may require more specific equipment instructions.

Third, it should also be acknowledged that the air contamination level at home, and gender, are factors associated with how well the children use the dosimeters (table 2). Our logistic regression analyses confirmed that children who had lower air dose rates at home were less likely to wear the dosimeters at school and that male children were less likely to use the dosimeters at school than were female children. These results may reflect the greater concerns of parents about the risk of radiation exposure for female children in particular, who have the greatest risk of future health problems.

Fourth, membership in outdoor sports clubs and hours spent outdoors on weekends were also associated with non-use of the dosimeters outdoors (table 2). These results imply that children who like outdoor activities tended to avoid wearing a dosimeter outdoors, possibly because they felt uncomfortable with it when they played outdoors.

Given these findings regarding the profiles of children who do not use the dosimeters properly, well-targeted instructions for particular groups of children should improve the rate of proper dosimeter use in children. However, more importantly, we must also consider the possibility that excessive or repeated instructions can be far more stressful for children and affect their everyday lives. Further discussion is expected in the future on how best to instruct children.

Importantly, the error (ie, the difference between the measured dose and regression estimates of the 'expected' dose) generated by improper use of the Glass Badge was almost $0 \mathrm{mSv}$ (ratio: 0.99$)$ overall $(\mathrm{n}=1518)$, with no statistical significance (table 3). This result indicates that even if the dosimeters are not properly used, solid evaluation of the radiation exposure may be possible with some accuracy.

When children removed the dosimeters, the dosimeters were generally left somewhere inside the home or school. This means that if the dosimeters are removed when children are at home or at school, the dosimeters can detect the radiation emitted from the same environment at similar exposure levels to those where the children are currently located. However, if children do not wear or bring the dosimeters to school or outdoors, this implies that the dosimeters and the children are in different environments with different radiation levels. Therefore, there are two possible reasons for this small error: the gap in radiation levels was very small between places where children spent most of the day and places where the dosimeters detected radiation without the child nearby, and most of the children in this study did not spend much time outdoors during the screening period.

These assumptions were supported by the fact that when the errors for each time period were compared, statistically significant differences were observed among children who did not wear or bring the dosimeters to school $(\mathrm{p}<0.01)$, whereas non-use at school or at home and during bedtime did not result in significant errors. Because children spend most of the day at school, if they do not wear or bring the dosimeters to school and the dosimeters are left in the home, the dosimeters measure the radiation in the home for a long period of time while the children are in school. Owing to successful decontamination of schools as well as schools' structural properties, there was a large gap in radiation levels between participants' dwelling location and the school grounds (mean of 0.49 and $0.11 \mu \mathrm{Sv} / \mathrm{h}$, respectively, including the natural background from the earth). As a result, the measured dose of children who did not wear or bring the dosimeters to school, where the radiation level was much lower than at home, was overestimated (ratio: 1.13; difference: $0.04 \mathrm{mSv}$; $\mathrm{p}<0.01$ ). However, this $0.04 \mathrm{mSv}$ difference in 3 months (an approximately annual dose of $0.12 \mathrm{mSv}$ ) is not clinically significant.

However, although it is not clinically significant, the finding that the measured values in those who did not use the dosimeters outdoors were significantly underestimated (ratio: 0.97; difference: $0.01 \mathrm{mSv}$; $\mathrm{p}<0.05$ ), deserves careful consideration. This small error was attributed to the fact that most of the children in this study did not spend much time outdoors during the 
screening period $(88 \%$ spent $<1 \mathrm{~h}$ outdoors after school, and $86 \%$ spent $<2 \mathrm{~h}$ outdoors on weekends). This means that the magnitude of the error due to non-use outdoors is determined by the amount of time children spend outdoors, as the dosimeters were left indoors, in addition to the difference in indoor and outdoor radiation levels; consequently, the measured dose can be underestimated.

The major determinant of the total dose is the radiation level of places where people spend most of the day. Therefore, it is reasonable to think that a major contributor to the significance of the errors may be the difference between the radiation levels in places where children are and those where the dosimeters are left. Our study considered school children, who tend to spend most of the day at school or home and who follow a similar schedule every day. Therefore, given that children who do not go to school (eg, preschool children), children on a long holiday or vacation break, and older children who are employed, have a different schedule, it is necessary to be careful when generalising our findings.

\section{Limitations}

We have identified some limitations in this study. First, note that the mean air dose rate in Minamisoma City during the study period was $0.49 \mu \mathrm{Sv} / \mathrm{h}$ (range 0.19$2.13 \mu \mathrm{Sv} / \mathrm{h}$ ). Because the absolute values of the errors generated by improper use of the dosimeters may depend on the air contamination level in people's living areas, our findings with regard to the significance of the errors are not generalisable to other areas with higher exposure levels in the Fukushima Prefecture. In addition, in this study, we did not adjust the measured dose for the body size of an individual and directly used the measured dose as his/her effective dose. It is known that there is a possibility that the body size of an individual affects the accuracy of an individual radiation dosimeter by, at maximum, about $10 \%$, depending on the product type as well as the irradiation geometry in the environment. ${ }^{25}$ However, given the small percentages, this potential body size-dependent inaccuracy does not influence our conclusions.

\section{CONCLUSIONS}

This study identified a low rate of proper Glass Badge use by children, which was primarily attributed to non-use of the Glass Badge at home and outdoors, rather than at school. More rigorous instructions on the use of the dosimeter are required, with particular focus on time periods other than school hours. Specific attention to younger children is also needed because of the difficulty in making them adhere to the appropriate use of the dosimeters. The error resulting from improper use of the dosimeters was very small and clinically unimportant, indicating that, even if the dosimeters are not properly used, a solid evaluation of radiation exposure may be possible with some accuracy. Note, however, that the error can rise to a significant level if children do not wear or bring the dosimeters to school and outdoors because the error is generated by the difference between the radiation levels in the places where they are and those where the dosimeters are left. This information is useful for developing appropriate radiation evaluation and protection policies in response to the present Fukushima incident as well as for future radiological incidents.

\section{Author affiliations}

${ }^{1}$ Department of Epidemiology and Biostatistics, School of Public Health, Imperial College London, London, UK

${ }^{2}$ Department of Radiation Protection, Minamisoma Municipal General Hospital, Fukushima, Japan

${ }^{3}$ Division of Social Communication System for Advanced Clinical Research, The Institute of Medical Science, University of Tokyo, Tokyo, Japan

${ }^{4}$ Department of Physics, Graduate School of Science, University of Tokyo,

Tokyo, Japan

${ }^{5}$ Department of Statistical Science, School of Advanced Sciences, The Graduate University for Advanced Studies, Tokyo, Japan

${ }^{6}$ Faculty of Policy Management, Keio University, Fujisawa, Kanagawa, Japan

Acknowledgements The authors express their gratitude to the Minamisoma City employees and MMGH staff for data collection and management. The authors are particularly grateful for the assistance given by Mr Kikugoro Sakaihara and Mr Masatsugu Tanaki from the MMGH, in geocoding the household addresses of the study participants and for technical support in the implementation of this study given by Professor Masahiro Kami from the University of Tokyo. They also offer special thanks to all study participants, without their involvement, the study could not have reached its present form.

Contributors All the authors were responsible for the study concept and design. MT, YK and TO acquired the data, which was analysed and interpreted by all the authors. SN, MT, AO and YS drafted the manuscript, which was critically revised for important intellectual content by all the authors. SN and DY performed the statistical analyses. YK and TO provided administrative, technical and material support. RH, TF and TO served as the study supervisors. All the authors have approved the final draft of the manuscript.

Funding This research received no specific grant from any funding agency in the public, commercial, or not-for-profit sector.

Competing interests None declared.

Ethics approval Ethical approval for this study was granted by the ethics committee of MMGH under authorisation number 25-08.

Provenance and peer review Not commissioned; externally peer reviewed.

Data sharing statement No additional data are available.

Open Access This is an Open Access article distributed in accordance with the Creative Commons Attribution Non Commercial (CC BY-NC 4.0) license, which permits others to distribute, remix, adapt, build upon this work noncommercially, and license their derivative works on different terms, provided the original work is properly cited and the use is non-commercial. See: http:// creativecommons.org/licenses/by-nc/4.0/

\section{REFERENCES}

1. World Health Organization. Preliminary dose estimation from the nuclear accident after the 2011 Great East Japan earthquake and tsunami. Geneva: World Health Organization, 2012.

2. World Health Organization. Health risk assessment from the nuclear accident after the 2011 Great East Japan earthquake and tsunami, based on a preliminary dose estimation. Geneva: World Health Organization, 2013.

3. Hayano RS, Tsubokura M, Miyazaki M, et al. Whole-body counter surveys of Miharu-town school children for four consecutive years after the Fukushima NPP accident. Proc Jpn Acad Ser B Phys Biol Sci 2015;91:92-8. 
4. Tsubokura M, Gilmour S, Takahashi K, et al. Internal radiation exposure after the Fukushima nuclear power plant disaster. JAMA 2012;308:669-70

5. Tsubokura M, Kato S, Nomura S, et al. Reduction of high levels of internal radio-contamination by dietary intervention in residents of areas affected by the Fukushima Daiichi nuclear plant disaster: a case series. PLOS ONE 2014;9:e100302.

6. Hayano RS, Tsubokura M, Miyazaki M, et al. Internal radiocesium contamination of adults and children in Fukushima 7 to 20 months after the Fukushima NPP accident as measured by extensive whole-body-counter surveys. Proc Jpn Acad Ser B Phys Biol Sci 2013;89:157-63.

7. Tsubokura M, Kato S, Morita T, et al. Assessment of the annual additional effective doses amongst Minamisoma children during the second year after the Fukushima Daiichi Nuclear Power Plant disaster. PLOS ONE 2015;10:e0129114.

8. United Nations Scientific Committee on the Effects of Atomic Radiation. Annex J: exposures and effects of the Chernobyl accident. New York: United Nations Scientific Committee on the Effects of Atomic Radiation, 2008.

9. Naito W, Uesaka M, Yamada C, et al. Evaluation of dose from external irradiation for individuals living in areas affected by the Fukushima Daiichi Nuclear Plant accident. Radiat Prot Dosimetry 2015;163:353-61.

10. National Institute of Radiological Sciences, Japan Atomic Energy Agency. Researches on the characteristics of personal doses after the accident of TEPCO Fukushima Dai-ichi Nuclear Power Plant. Chiba, 2014.

11. United Nations Scientific Committee on the Effects of Atomic Radiation. Annex A: levels and effects of radiation exposure due to the nuclear accident after the 2011 Great East-Japan earthquake and tsunami. New York: United Nations Scientific Committee on the Effects of Atomic Radiation, 2014

12. Nomura S, Tsubokura M, Hayano R, et al. Comparison between direct measurements and modeled estimates of external radiation exposure among school children 18 to 30 months after the Fukushima nuclear accident in Japan. Environ Sci Technol 2015;49:1009-16.

13. Orita M, Hayashida N, Taira $\mathrm{Y}$, et al. Measurement of individual doses of radiation by personal dosimeter is important for the return of residents from evacuation order areas after nuclear disaster. PLOS ONE 2015;10:e0121990.

14. Nagataki S, Takamura N, Kamiya K, et al. Measurements of individual radiation doses in residents living around the Fukushima Nuclear Power Plant. Radiat Res Nov 2013:180:439-47.

15. International Commission on Radiological Protection. ICRP Publication 103: Recommendations of the ICRP. New York, 2013.

16. Miyazaki M, Hayano R. Current individual radiation measurement in Fukushima. Isotope News 2014;10:28-32 (in Japanese).

17. Chiyoda Technol Corporation. Glass Badge Technical Specification [Japanese]. Tokyo: Chiyoda Technol Corporation, 2012.

18. Hirayama $\mathrm{H}$. An evaluation of personal dosimeter for widely distributed ${ }^{134} \mathrm{Cs}$ and ${ }^{137} \mathrm{Cs}$ by using EGS code. Radioisotopes 2013;62:335-45.

19. Nakamura T. Post accident radiation monitoring in the surrounding environment. Prog Nucl Sci Technol 2012;3:30-5.

20. Ministry of Education, Culture, Sports, Science and Technology. Results of the (i) fifth airborne monitoring survey and (ii) airborne monitoring survey outside $80 \mathrm{~km}$ from the Fukushima Dai-ichi NPP. http://radioactivity.nsr.go.jp/en/contents/6000/5790/24/203_0928_ 14e.pdf (accessed 10 Oct 2015).

21. Ministry of Education, Culture, Sports, Science and Technology. Results of the (i) sixth airborne monitoring and (ii) airborne monitoring out of the $80 \mathrm{~km}$ from the Fukushima Dai-ichi NPP. http:// radioactivity.nsr.go.jp/en/contents/7000/6099/24/203_e_0301_18.pdf (accessed 10 Oct 2015)

22. Ministry of Land, Infrastructure and Transport. Japan Profile for Geographic Information Standards. http://www.gsi.go.jp/ENGLISH/ page e30210.html (accessed 10 Oct 2015).

23. McCuen RH. Modeling hydrologic change: statistical methods. Florida: Lewis Publishers, 2003.

24. Speybroeck N. Classification and regression trees. Int J Public Health 2012;57:243-6.

25. National Institute of Radiological Sciences. Additional research on the characteristics of an individual radiation dosimeter pertaining to the Tokyo Electric Power Company's Fukushima Daiichi Nuclear Power Plant accident-consideration of the estimation method of individual dose in children. http://www.nirs.go. jp/information/event/report/2015/03_16/houkokusho5.pdf (accessed 10 Oct 2015) 